\title{
Measurement and Simulation Results of Ti Coated Microwave Absorber (TT2-111)
}

\author{
Ding Sun and Dave McGinnis
}

$11 / 98$

\section{Introduction}

When microwave absorbers are put in a waveguide, a layer of resistive coating can change the distribution of the E-M fields and affect the attenuation of the signal within the microwave absorbers. In order to study such effect, microwave absorbers (TT2-111) were coated with titanium thin film. This report is a document on the coating process and measurement results. The measurement results have been used to check the simulation results from commercial software HFSS (High Frequency Structure Simulator.)

\section{Sample Description}

TT2-111 samples were cut into rectangular shape (0.795 in $\times 1.98$ in). Sixteen pieces were ground to 0.065 inch thick and 8 pieces were ground to 0.125 inch thick. Samples were divided into 6 groups. Samples (4 pieces) in each group are the same size and coated together. Half of these samples (group 4-6) were sputtered with Ti at Fermilab (Lab 7,) and half of them (group 1-3) were sputtered with Ti at Thin Film Technology Inc., California. The thickness of Ti thin film coated at Fermilab (Group 4-6) is $137 \mathrm{~A}^{\circ}$ $141 \mathrm{~A}^{\circ}$. The corresponding surface resistance is $\sim 260 \Omega / \Omega$ square $\sim 210 \Omega$ / square. The thickness of $\mathrm{Ti}$ thin film coated at Thin Film Technology Inc. (Group 1-3) is $\sim 216 A^{\circ}$. The corresponding surface resistance is $\sim 252$ $\Omega /$ square - $216 \Omega /$ square. Listed in Table 1 are the detailed description.

Note: apparently there is a discrepancy between Fermilab and Thin Film Technology Inc. on calibrations of thickness monitors. However, this does not matter since the surface resistance is the only factor to be considered.

In order to see the stability of the thin film, surface resistance was measured immediately after coating and 7-10 days later. There was no significant change.

\section{Measurement Results}

$S$ parameters were measured before and after resistive coating using a 6" long waveguide (WR159). Four pieces of samples (a group) were measured each time. Samples were put against inner surfaces of two narrow sides of the waveguide (two pieces of samples on each side, see Figure 11.) Shown in Figure 1-6 are the measured S21 parameters of each group.

All results show that attenuation was decreased after resistive coating. Shown in Figure 7 and 8 are the measured S11 parameters for two groups of samples (S11 of other 
groups of samples are similar to theses two groups.) The fact that the S11 did not increase means that the increase of S21 was due to the decreased attenuation which is due to the re-distribution of field.

The measured results are very close to each other between samples with same thickness. This indicates that the E-M properties of TT2-111 tiles are consistent (at least within a batch.)

\section{Simulation Results}

As a comparison, shown in Figure 9 and 10 are simulation results (only 11 points were calculated between $5 \mathrm{GHz}$ and $7 \mathrm{GHz}$ ) using software HFSS from Ansoft (v. 6 beta.) Simulation results from HFSS (v.5) of Hewlett Packard are almost the same as that from Ansoft. Thickness of the absorbers used in simulation is 0.065 inch, so these simulation results should be compared with the measured results of sample group 1,2, 4 or 5 . At 6 $\mathrm{GHz}$ (the frequency at which the meshes were refined in the simulation), the difference between the measured results (group 4) and the simulation results are only $\sim 0.2 \mathrm{db}$. At other frequencies the difference are larger. The following factors may contribute to the errors in simulation: (1) the values of E-M properties of the absorber material (permittivity, permeability and loss tangent) used in the simulation for all frequencies are the values measured at $6 \mathrm{GHz}$; (2) refinement of the mesh in simulation was at single frequency of $6 \mathrm{GHz}$; (3) the unavoidable error in measurement of these properties. Since the absorbers are thin and coated, it is a challenge the capability and accuracy of simulation software. So the above comparison may be served as one of evaluations of the simulation software HFSS.

Table 1. Sample Description

\begin{tabular}{|l|l|l|lr|l|}
\hline Group \# & $\begin{array}{l}\text { Thickness of } \\
\text { Absorber }\end{array}$ & $\begin{array}{l}\text { Thickness of } \\
\text { Ti film }\end{array}$ & $\begin{array}{l}\text { Surface } \\
\text { Resistance }\end{array}$ & Coated by: \\
\hline 1 & $0.065^{\prime \prime}$ & $216 \mathrm{~A}^{\circ}$ & $\begin{array}{l}230-240 \\
\Omega / \\
\text { uare }\end{array}$ & sq & Thin Film Tech. \\
\hline 2 & $0.065^{\prime \prime}$ & $216 \mathrm{~A}^{\circ}$ & $\begin{array}{l}216-252 \\
\Omega / \\
\text { uare }\end{array}$ & sq & Thin Film Tech. \\
\hline 3 & $0.125^{\prime \prime}$ & $216 \mathrm{~A}^{\circ}$ & $\begin{array}{l}230-240 \\
\Omega / \\
\text { uare }\end{array}$ & sq & Thin Film Tech. \\
\hline 4 & $0.065^{\prime \prime}$ & $137 \mathrm{~A}^{\circ}$ & $\begin{array}{l}240-260 \\
\Omega / \\
\text { uare }\end{array}$ & sq & Fermilab \\
\hline 5 & $0.065^{\prime \prime}$ & $141 \mathrm{~A}^{\circ}$ & $\begin{array}{l}210-230 \\
\Omega /\end{array}$ \\
& & sqare & Fermilab \\
\hline
\end{tabular}




\begin{tabular}{|c|c|c|c|c|}
\hline 6 & $0.125 "$ & $141 \mathrm{~A}^{\circ}$ & $\begin{array}{l}210-230 \\
\Omega / \\
\text { uare }\end{array}$ & Fermilab \\
\hline
\end{tabular}

Figure 1. S21 of Sample Group 1

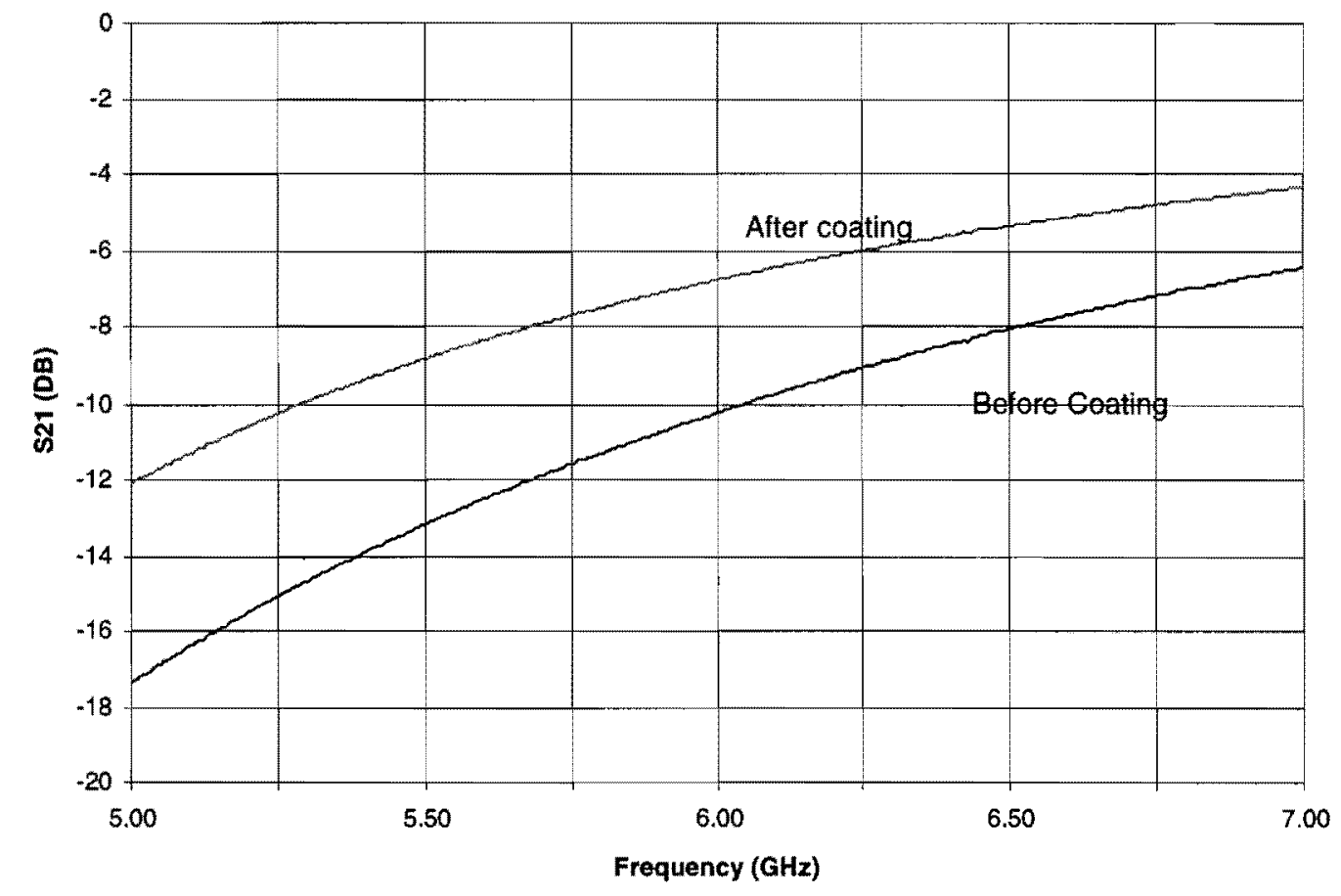


Figure 2. S21 of Sample Group 2

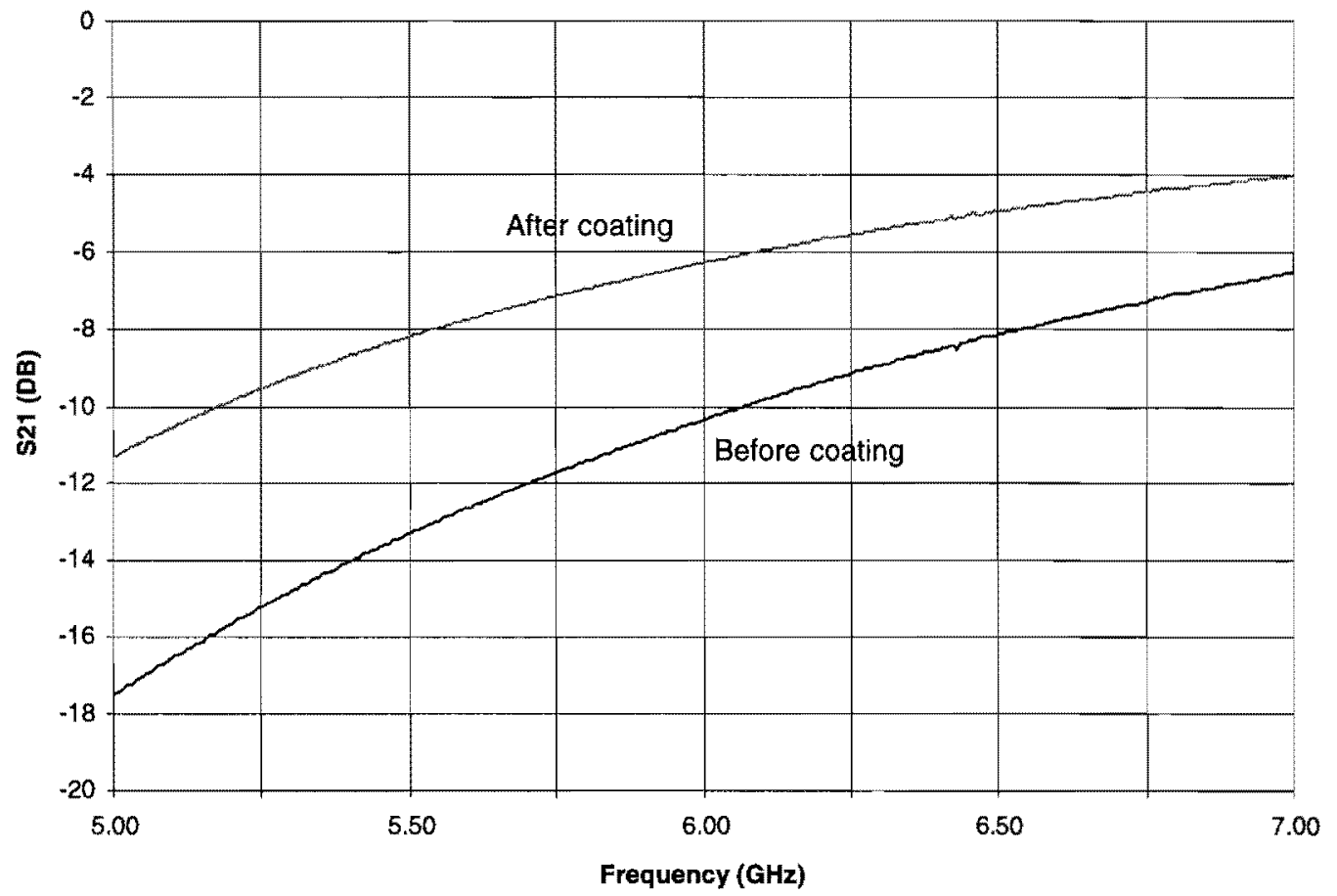

Figure 3. S21 of Sample Group 3

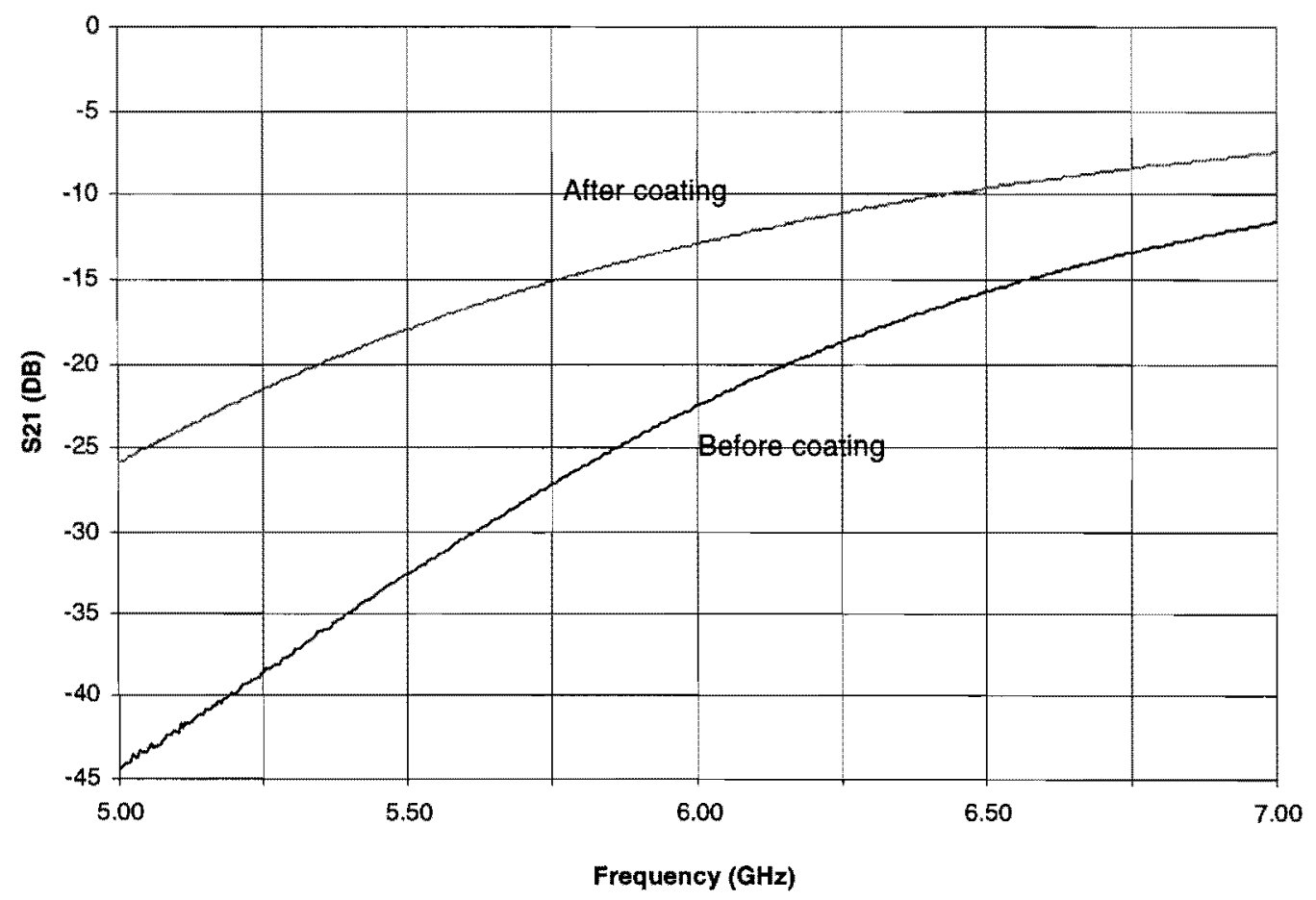




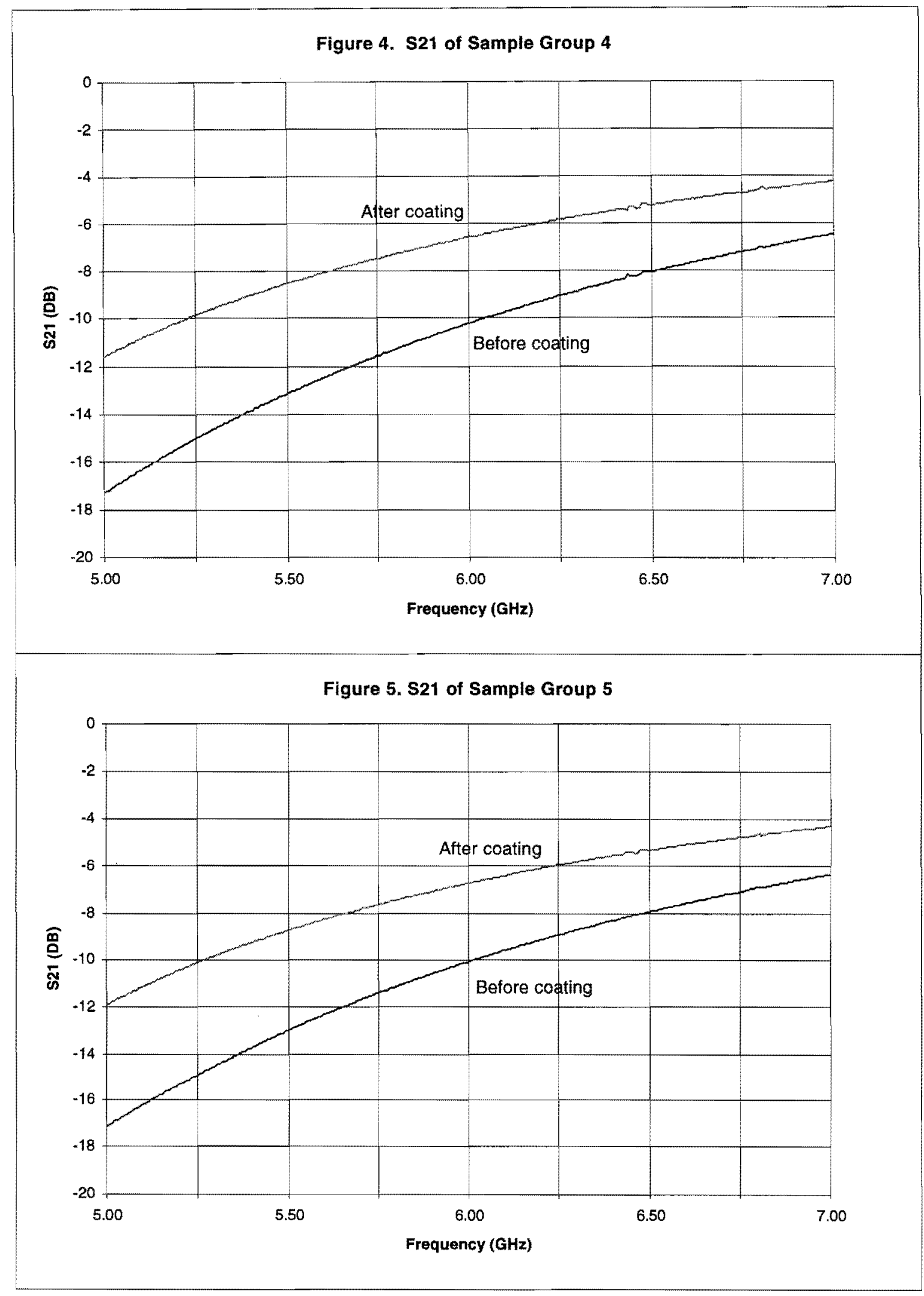


Figure 6. S21 of Sample Group 6

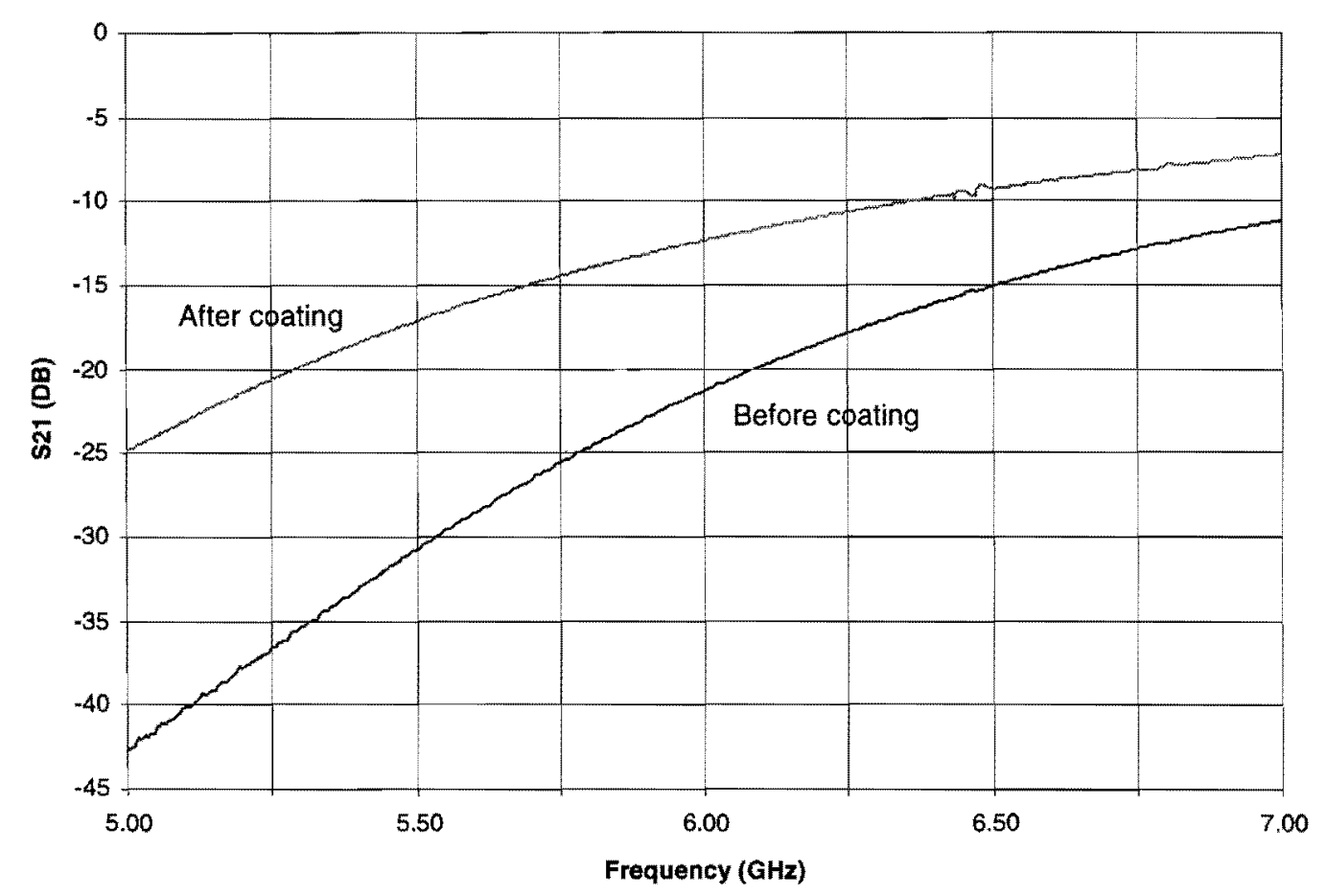

Figure 7. S11 of Sample Group 4

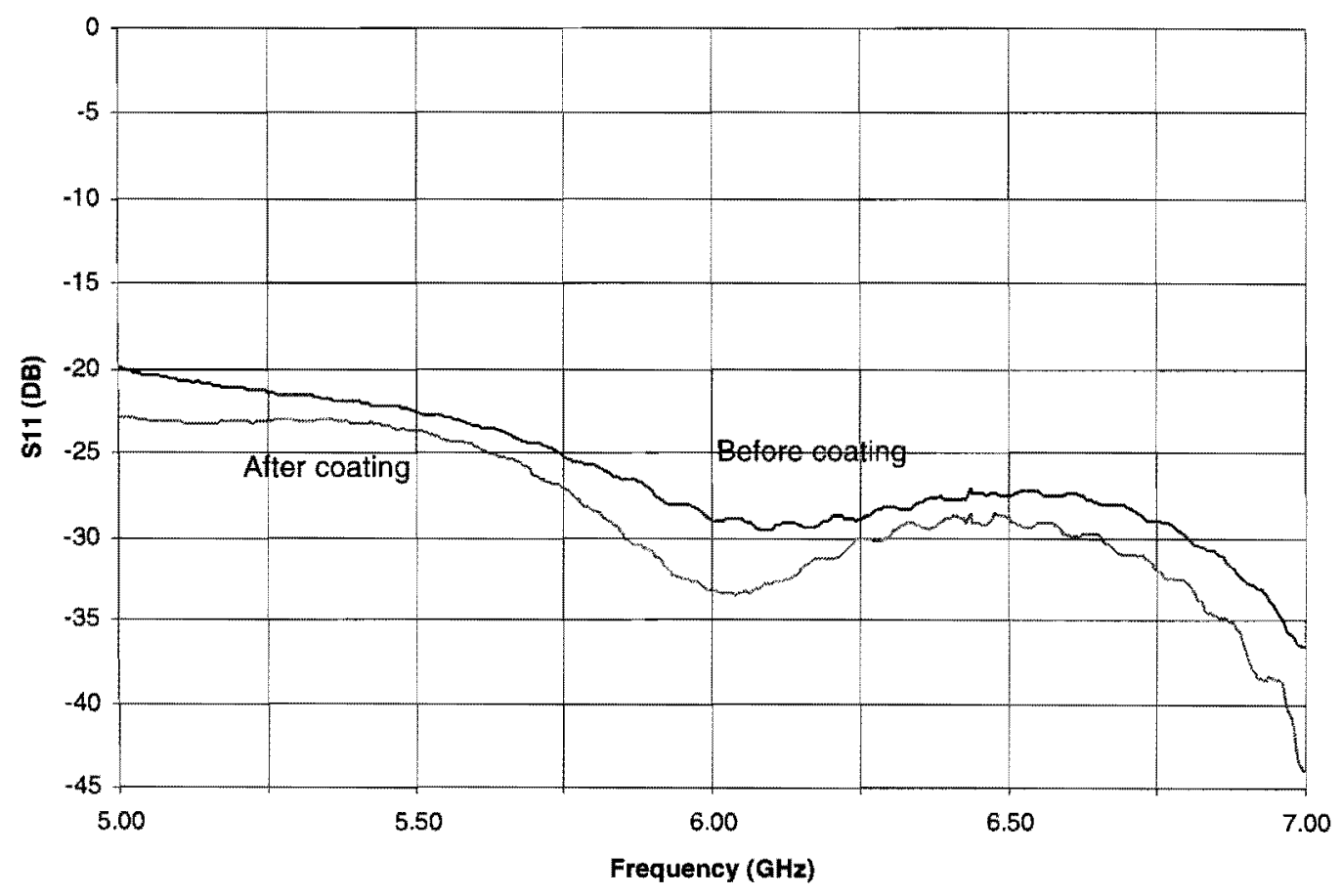




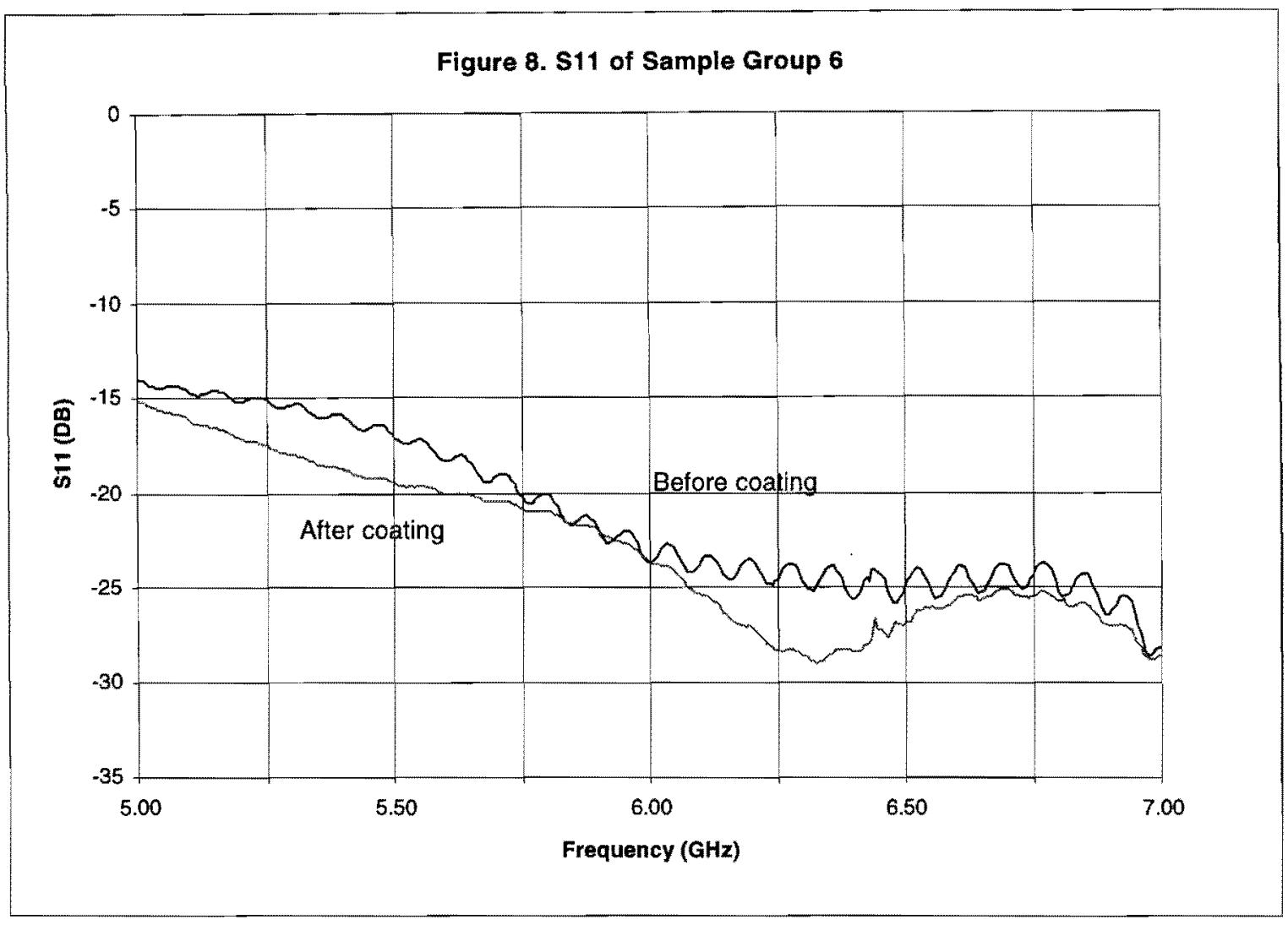

Figure 9. S21 of Simulation Results (HFSS v.6 Ansoft)

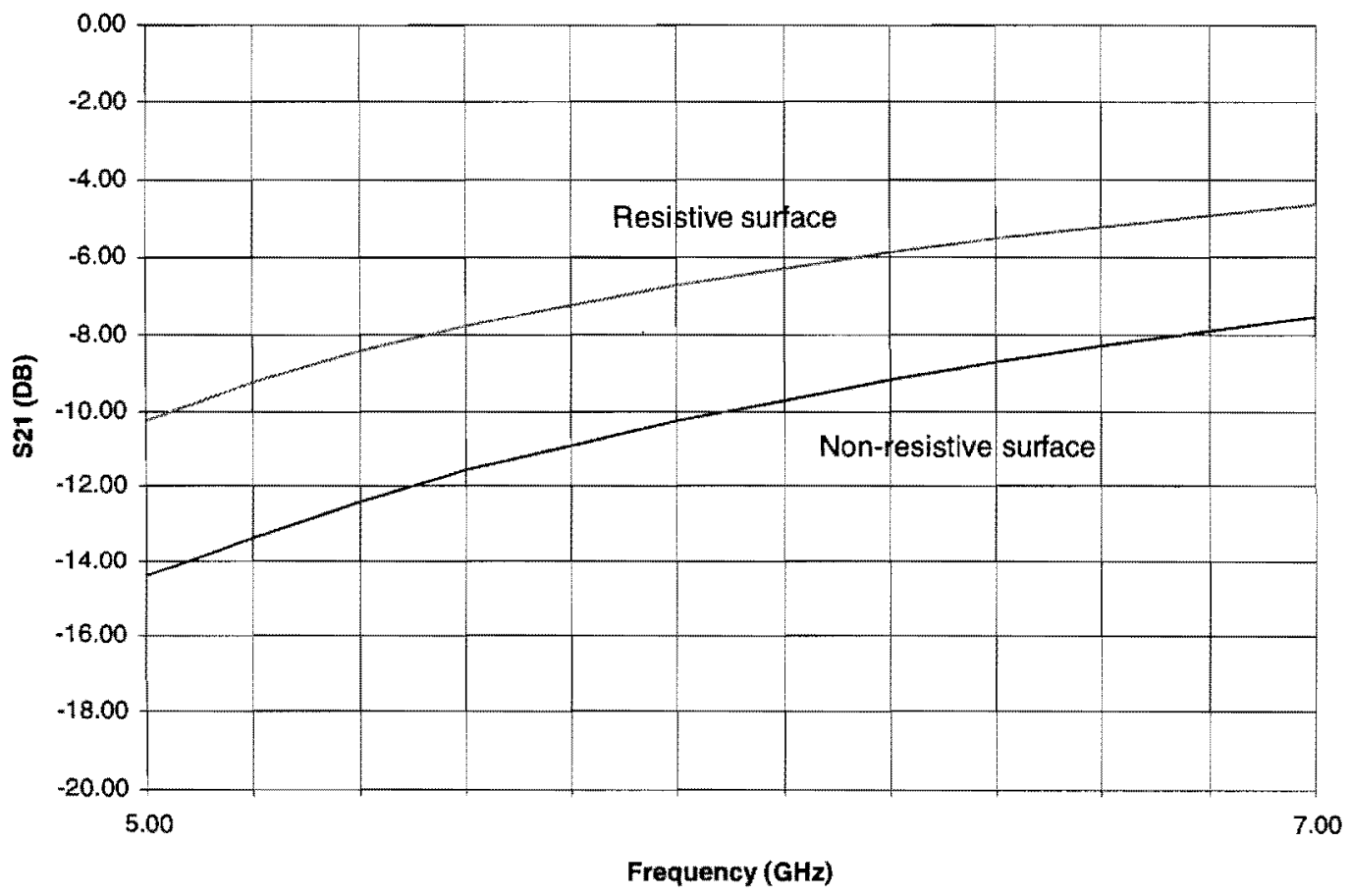




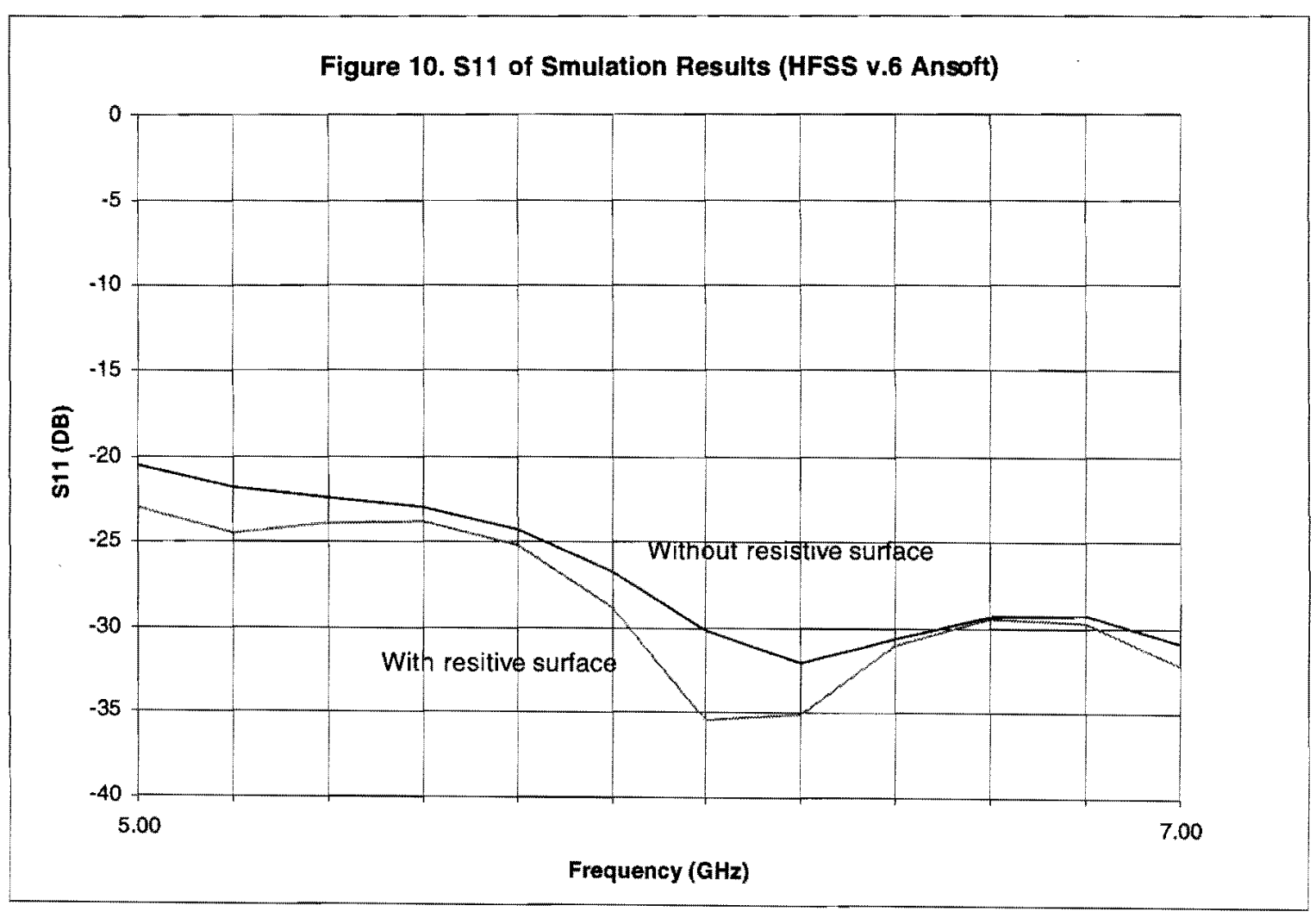

Figure 11. Schamatic Drawing of Configuration of Microwave Absorber

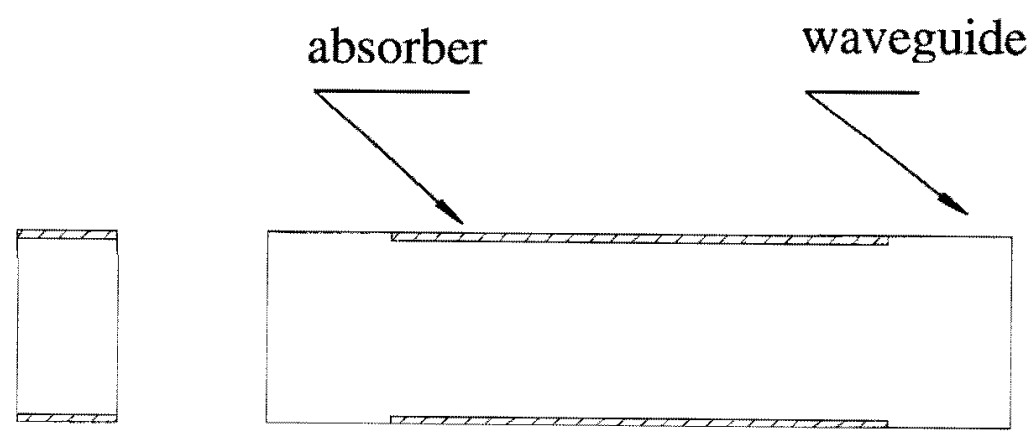

